\title{
Solitary Nucleus
}

National Cancer Institute

\section{Source}

National Cancer Institute. Solitary Nucleus. NCI Thesaurus. Code C13067.

A cluster of nerve cell bodies that form a column of gray matter in the dorsomedial region of the medulla oblongata. The solitary nucleus comprises the gustatory and visceral sensory nuclei of the brainstem, processing impulses from the taste buds, pharynx, larynx, intestinal and respiratory tracts, heart, and large blood vessels. 